\title{
Do not invade, just support
}

\author{
ZENGIN Musa', KARCIOGLU Ayse Muge² \\ University of Health Sciences, Ankara Ataturk Chest Diseases and Thoracic Surgery Training and Research \\ Hospital, Anesthesiology and Reanimation Clinic, Ankara, Turkey. musazengin@gmail.com
}

\begin{abstract}
BACKGROUND: Since the first attempts for ventilation, there have been significant changes in terms of the size of devices, ventilation techniques, and technology. In time, invasive methods and huge devices were replaced by non-invasive methods and small and portable devices. Increased use of non-invasive methods was followed by enrichment of literature on the topic. This study aimed to determine the evolution of noninvasive ventilation (NIV) literature and predict future trends.

MATERIALS AND METHODS: We used the Web of Science database for search. To include all papers, we searched multiple keywords, including "non-invasive ventilation, non-invasive positive pressure, continuous positive airway pressure, CPAP, NIV." All articles that meet the criteria published in the respiratory system, critical care medicine, anesthesiology, and emergency medicine fields during 1975-2020 were determined. RESULTS: We made bibliometric analyses of 2847 original articles. However, the limited number of articles in the first years, published by year, exceeded a hundred with the new millennium and continues to increase. We predict that 233 and 334 papers will be published in 2021-2025, respectively. Most active countries were United States of America (576, 20.2 \%), France (395, $13.8 \%$ ), Italy (293, $10.2 \%)$. The most used keywords in NIV papers are non-invasive ventilation, continuous positive airway pressure and obstructive sleep apnea. CONCLUSION: NIV technology and new devices are developing day by day. In addition, new areas of use have been defined by doctors. All these bring about new and different studies on NIV. We believe the present study that summarized the history and development of NIV literature will guide the authors who want to study this area (Tab. 4, Fig. 8, Ref. 19). Text in PDF www.elis.sk KEYWORDS: bibliography, COPD, history, non-invasive ventilation, respiratory failure.
\end{abstract}

\section{Introduction}

The history of respiratory treatment began with the use of oxygen by Thomas Beddoes, the father of respiratory therapy, in the late 1700s, accelerated with the polio epidemic in the 1950s in Europe, and resulted in the discovery of highly skilled ventilators after the 1980s (1-3). During the polio epidemic, the first use of non-invasive ventilation started with negative pressure ventilators supporting ventilation by exposing the surface of the thorax to subatmospheric pressure. But it couldn't be widely used because of giant machines, patients' poor compliance, and its benefits weren't supported by prospective studies.

Invasive ventilation has devastating effects on patients, including using an endotracheal tube, the need for sedation because the

\footnotetext{
${ }^{1}$ University of Health Sciences, Ankara Ataturk Chest Diseases and Thoracic Surgery Training and Research Hospital, Anesthesiology and Reanimation Clinic, Ankara, Turkey, and ${ }^{2}$ Ministry of Health Ankara City Hospital, Department of Intensive Care, Ankara, Turkey

Address for correspondence: M. Zengin, M.D., Kuscagiz Mah. Sanatoryum Cad. No: 271, University of Health Sciences, Ankara Ataturk Chest Diseases and Thoracic Surgery Training and Research Hospital, Anesthesiology and Reanimation Clinic, Ankara, Turkey Phone: 00905307716235
}

endotracheal tube is hard to tolerate, impaired cough, and conclusion with tracheostomy in case of prolonged intubation. The discovery of non-invasive positive-pressure ventilation met the remaining demand for non-invasive ventilation. This technique allowed to deliver needed tidal volume by a nasal, oronasal, or

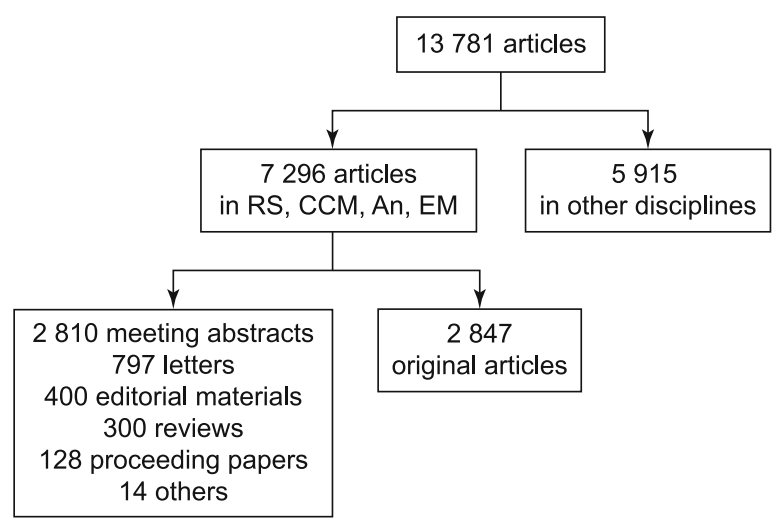

Fig. 1. Diagram of Articles. Others: book chapter, correction note, early access, biographical item, book/book review, correction addition, news item, reprint, retracted publication. An: Anesthesia, CCM: Critical Care Medicine, EM: Emergency Medicine, RS: Respiratory System. 
face mask and maintain the oral feeding and cough reflex. The improved machines allow enough volume and pressure, and they started to be used for several acute and chronic ventilatory disorders in the second half of the 1970s. The increasing number of intensive care units using non-invasive ventilators and expanding the use area bring new literature. Since then, numerous articles have been published examining non-invasive ventilation.

Bibliometrics is the analysis of scientific outputs and articles using statistical methods (4). Bibliometric analyses enable determining the most cited influential studies and journals, the most researched trending topics, the most active countries, institutions, journals, or authors in a subject or a research field (5). In addition, the general research trend of a subject in the world can be determined by introducing international collaborations.

This study aims to investigate non-invasive literature, define cornerstone papers, most productive authors, and countries, determine the top journals, and predict the future of non-invasive ventilation literature.

\section{Materials and methods}

We used the Web of Science (WoS) database for search. To include all papers about non-invasive ventilation, we searched the following keywords in WoS "non-inva- sive ventilation, non-invasive ventilation, non-invasive mechanical ventilation, non-invasive mechanical ventilation, continuous positive airway pressure, CPAP, bilevel positive airway pressure, $B P A P, B i P A P$, High flow nasal cannula, HFNC, non-invasive positive pressure, NIPPV, and NIV" in the "title" section of articles.

Tab. 1. Language distribution and citations.

\begin{tabular}{|c|c|c|c|c|}
\hline Language & Number of articles & \multirow{7}{*}{ 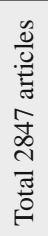 } & \multirow{2}{*}{ h- index } & \multirow{2}{*}{137} \\
\hline English & 2669 & & & \\
\hline French & 83 & & Average citations per article & 33,09 \\
\hline Spanish & 52 & & \multirow{2}{*}{ Sum of times cited } & \multirow{2}{*}{94202} \\
\hline German & 31 & & & \\
\hline Portuguese & 8 & & \multirow{2}{*}{ Without self-citations } & \multirow{2}{*}{78333} \\
\hline Turkish & 4 & & & \\
\hline
\end{tabular}

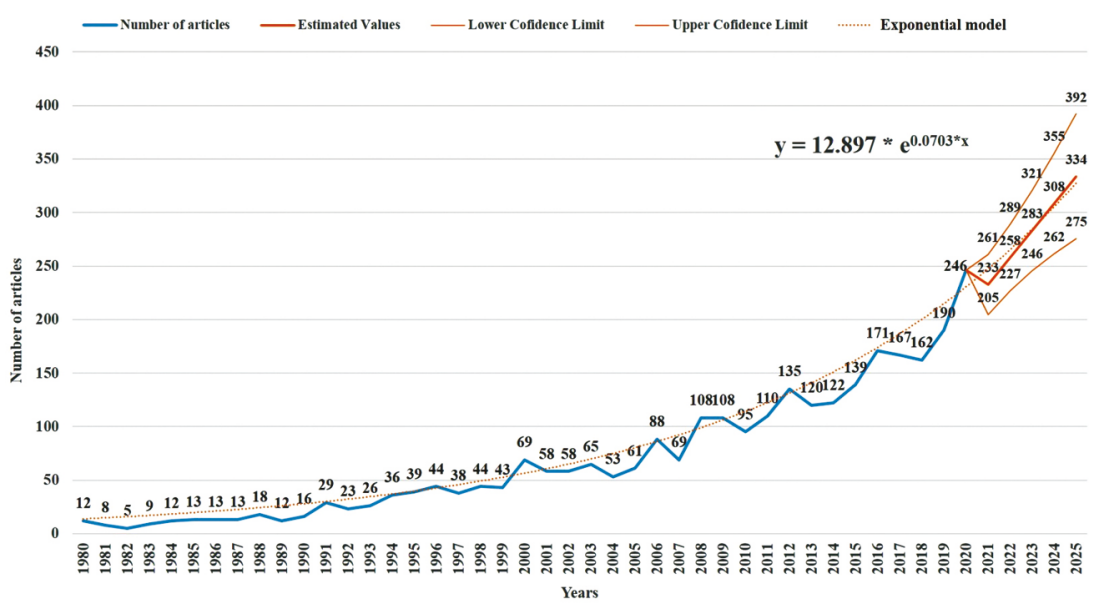

Fig. 2. Number of articles published on noninvasive ventilation by years and estimation of the number of articles that can be published in the future.

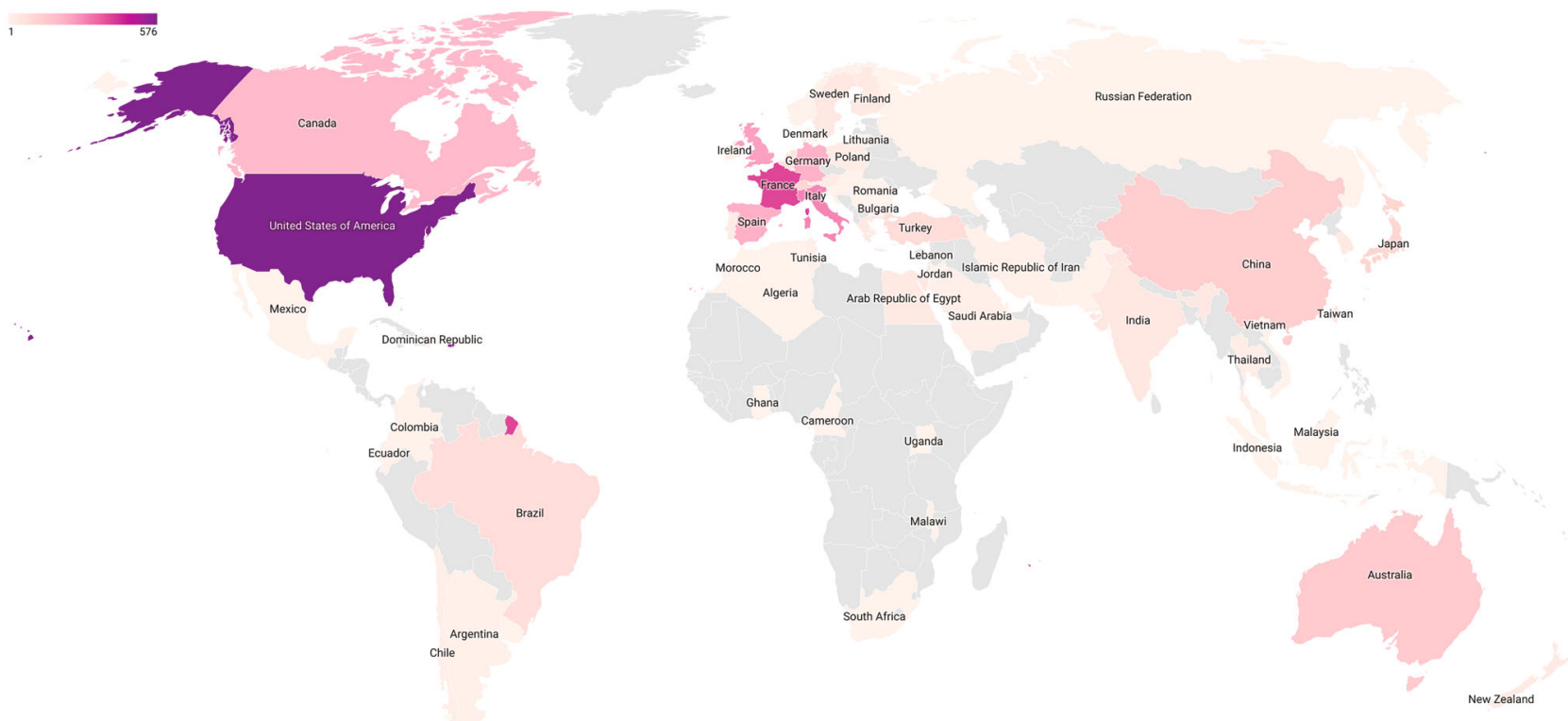

Fig. 3. World map for the distribution of articles by country on noninvasive ventilation. Footnote: In the indicator given at the bottom left of the figure, productivity increases from green to red. 


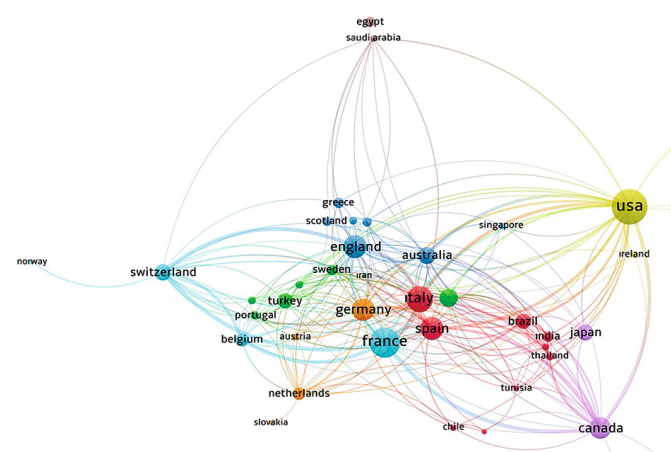

a

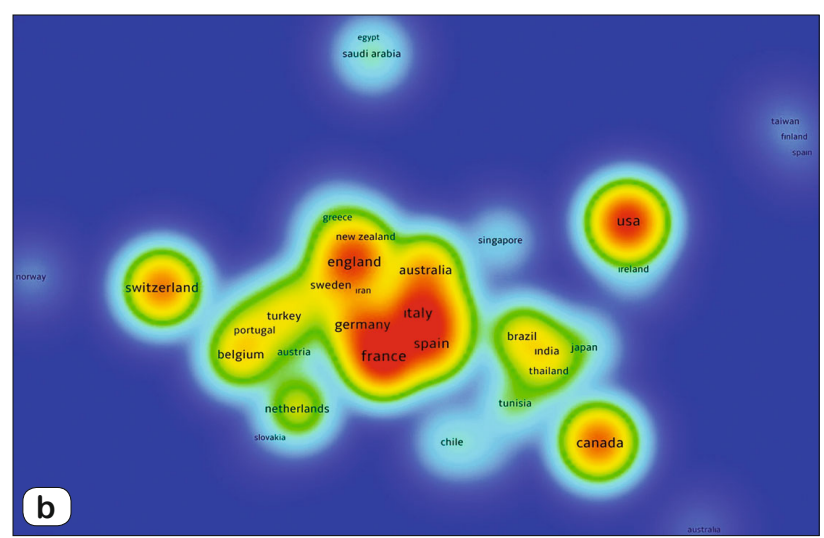

Fig. 4. a. Network visualization map for international collaboration of worldwide countries on noninvasive ventilation. The size of the circle shows the large number of articles, the thickness of the lines indicates the strength of relationship, and the colors show the different clusters. b. Density map for international collaboration of worldwide countries on noninvasive ventilation. Cooperation increases from blue to red (blue-green-yellow-red).

All articles that meet the criteria published in the respiratory system, critical care medicine, anesthesiology, and emergency medicine fields during 1975-2020 were determined. (Date of access: 15.05.2021). Reproducibility codes for researchers to reach similar documents (search findings may vary depending on different access dates): (title: ("non invasive ventilation") or title: ("noninvasive ventilation”) or title: ("non invasive mechanical ventilation") or title: ("noninvasive mechanical ventilation") or title: (“continuous positive airway pressure") or title: (“CPAP”) or title: ("bilevel positive airway pressure”) or title: ("BPAP”) or title: (“BiPAP”) ("non-invasive positive pressure”) or title: (“NIPPV”) or title: ("NIV") Refined by: web of science categories: (respiratory system or critical care medicine or anesthesiology or emergency medicine) Timespan: 1975-2020. Indexes: SCI-Expanded, SSCI, A\&HCI, CPCI-S, CPCI-SSH, BKCI-S, BKCI-SSH, ESCI).

VOS viewer (Version 1.6.15, Leiden University's Centre for Science and Technology Studies) was used for bibliometric network visualizations. We used the https://app.datawrapper.de website for world map graphics. Statistical analyses were performed by using SPSS software version 22.0 (SPSS Inc., Chicago, IL, ABD). The normal distribution of data was tested with the Kol-
Tab. 2. Top most active journals on non-invasive mechanical ventilation.

\begin{tabular}{|c|c|c|c|}
\hline Journals & $\mathrm{RC}$ & $\mathrm{C}$ & $\mathrm{AC}$ \\
\hline Chest & 263 & 16859 & 64.1 \\
\hline Respiratory Care & 235 & 4413 & 18.8 \\
\hline Sleep and Breathing & 200 & 2793 & 14.0 \\
\hline European Respiratory Journal & 146 & 8155 & 55.9 \\
\hline Intensive Care Medicine & 136 & 6768 & 49.8 \\
\hline $\begin{array}{l}\text { American Journal of Respiratory and } \\
\text { Critical Care Medicine }\end{array}$ & 120 & 16456 & 137.1 \\
\hline Pediatric Pulmonology & 96 & 2000 & 20.8 \\
\hline Thorax & 95 & 8065 & 84.9 \\
\hline Respiratory Medicine & 90 & 2380 & 26.4 \\
\hline Critical Care Medicine & 84 & 4580 & 54.5 \\
\hline Respiration & 66 & 1591 & 24.1 \\
\hline Revue Des Maladies Respiratoires & 59 & 164 & 2.8 \\
\hline Respirology & 54 & 847 & 15.7 \\
\hline Archivos de Bronconeumologia & 45 & 350 & 7.8 \\
\hline Critical Care & 36 & 1156 & 32.1 \\
\hline Journal of Critical Care & 35 & 721 & 20.6 \\
\hline Pediatric Critical Care Medicine & 35 & 789 & 22.5 \\
\hline Journal of Thoracic Disease & 34 & 188 & 5.5 \\
\hline American Review of Respiratory Disease & 32 & 4205 & 131.4 \\
\hline BMC Pulmonary Medicine & 30 & 424 & 14.1 \\
\hline Respiratory Physiology \& Neurobiology & 29 & 267 & 9.2 \\
\hline Clinical Respiratory Journal & 27 & 110 & 4.1 \\
\hline $\begin{array}{l}\text { International Journal of Chronic } \\
\text { Obstructive Pulmonary Disease }\end{array}$ & 27 & 342 & 12.7 \\
\hline Minerva Anestesiologica & 26 & 434 & 16.7 \\
\hline Acta Anaesthesiologica Scandinavica & 24 & 360 & 15 \\
\hline Anesthesia and Analgesia & 24 & 614 & 25.6 \\
\hline Anesthesiology & 22 & 838 & 38.1 \\
\hline American Journal of Emergency Medicine & 21 & 257 & 12.2 \\
\hline $\begin{array}{l}\text { Egyptian Journal of Chest Diseases and } \\
\text { Tuberculosis }\end{array}$ & 21 & 17 & 0.8 \\
\hline Canadian Respiratory Journal & 20 & 267 & 13.4 \\
\hline Lung & 20 & 603 & 30.2 \\
\hline Anaesthesia & 19 & 251 & 13.2 \\
\hline Emergency Medicine Journal & 18 & 401 & 22.3 \\
\hline Indian Journal of Critical Care Medicine & 17 & 44 & 2.6 \\
\hline Annals of Intensive Care & 16 & 255 & 15.9 \\
\hline Anaesthesia and Intensive Care & 15 & 108 & 7.2 \\
\hline British Journal of Anaesthesia & 15 & 193 & 12.9 \\
\hline Annals of the American Thoracic Society & 14 & 151 & 10.8 \\
\hline European Journal of Emergency Medicine & 14 & 209 & 14.9 \\
\hline BMJ Open Respiratory Research & 13 & 64 & 4.9 \\
\hline $\begin{array}{l}\text { Copd-Journal of Chronic Obstructive } \\
\text { Pulmonary Disease }\end{array}$ & 13 & 123 & 9.5 \\
\hline $\begin{array}{l}\text { Annales Francaises d Anesthesie et } \\
\text { de Reanimation }\end{array}$ & 12 & 143 & 11.9 \\
\hline ERJ Open Research & 12 & 34 & 2.8 \\
\hline Heart \& Lung & 12 & 140 & 11.7 \\
\hline Jornal Brasileiro De Pneumologia & 11 & 88 & 8 \\
\hline Respiratory Research & 11 & 275 & 25 \\
\hline $\begin{array}{l}\text { Journal of Aerosol Medicine and Pulmonary } \\
\text { Drug Delivery }\end{array}$ & 10 & 201 & 20.1 \\
\hline Journal of Intensive Care Medicine & 10 & 42 & 4.2 \\
\hline Medicina Intensiva & 10 & 87 & 8.7 \\
\hline
\end{tabular}

RC - Record Count, C - Number of Citation, AC - Average Citation Per Document 


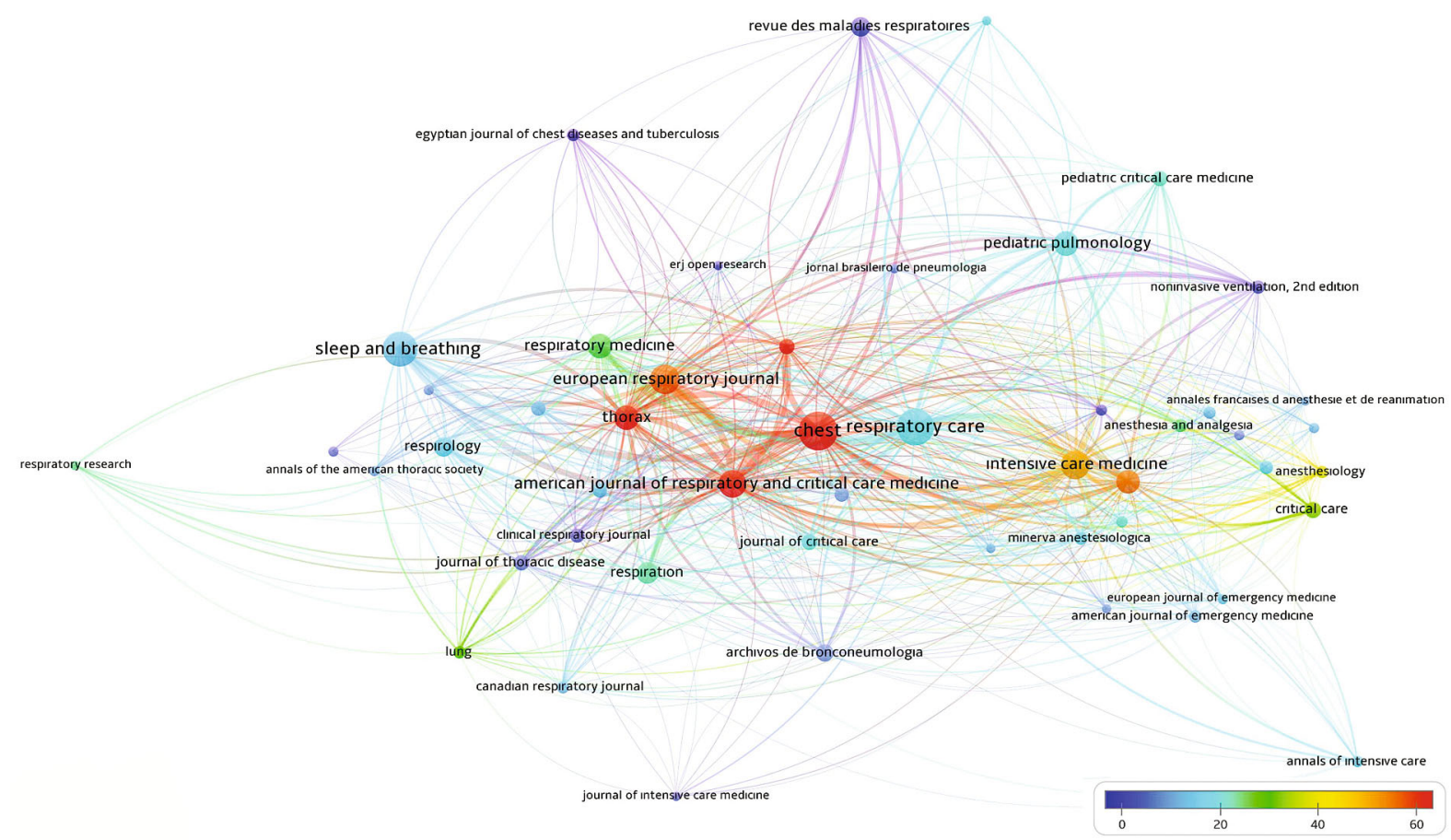

Fig. 5. Network visualization map for citation analysis of active journals on noninvasive ventilation. The size of the circle shows the large number of articles. The number of citations from blue to red (blue-green-yellow-red) increases.

mogorov-Smirnov test. Spearman correlation coefficient was used to determine the effective indicators on the academic productivity on NIV, the number of articles produced by the world countries, and some economic development indicators of the world countries (Gross Domestic Product (GDP), Gross Domestic Product per capita (GDP per capita), Gross Domestic Product per capita), whose data were obtained from the world bank (6).

We used non-linear regression analyses to predict the number of articles in the future. The R2 value was used to evaluate model success in regression analysis. $\mathrm{p}<0.05$ was determined to infer statistical significance.

\section{Results}

There was no published paper between 1975-1980 in the WoS database. 13781 articles were published during 1980-2020. 7296 were in "Respiratory system, critical care medicine, emergency medicine, and anesthesiology. 2847 (39\%) was original article, 2810 ( $38.5 \%$ ) was meeting abstract, 797 (10.9\%) was letter. The remaining 842 papers consisted of editorial materials (400, $5.5 \%$ ), reviews (300, $4.1 \%)$, proceedings papers (128, $1.8 \%$ ), and others (book chapter, correction note, early access, biographical item, book/book review, correction addition, news item, reprint, retracted publication). We made bibliometric analyses of 2847 original articles. 2669 (93.7 \%) of the total articles were written in English. The H-index of these articles was 137, the average citation per article was 33.09, and the sum of times cited was 94202 (78333 without self-citations) (Fig. 1, Tab. 1).
The trend of publication and future prediction

We used non-linear regression analysis (exponential model) to estimate the number of articles in 2021 and beyond. To the prediction model, 233 (CI\%: 205-261) and 334 (CI\%: 275-392) articles will be published in 2021 and 2025, respectively (Fig. 2).

\section{Active countries}

The countries that published most articles (20 and more articles) were United States of America (USA) (576, $20.2 \%$ ), France (395, $13.8 \%)$, Italy (293, $10.2 \%)$, United Kingdom (UK) (249, 7.6 \%), Spain (220, $7.7 \%$ ), Germany (206, $7.2 \%)$, (206, $7.2 \%)$, Canada (191, $6.7 \%)$, Australia (144, 5 \%), China (127, $4.4 \%)$, Japan (105, 3.6 \%), Switzerland (102, $3.5 \%$ ), Turkey (84, $2.9 \%$ ), Brazil (80, $2.8 \%$ ), Belgium (65, $2.2 \%)$, Netherlands (53, $1.8 \%$ ), Sweden (41, $1.4 \%)$, India (40, $1.4 \%)$, Greece (36, $1.2 \%)$, Taiwan (36, $1.2 \%$ ), and Finland (31, $1 \%$ ) (Fig. 3). The international collaboration network visualization map between 44 countries producing at least 5 articles from 75 countries producing publications on NIV and cooperating is shown in Figure 4a and density map Figure 4b.

\section{Correlation analysis}

A statistically positive high and moderate correlation was found between the number of articles produced by countries on NIV and GDP (Gross Domestic Product), GDP per capita, GDP PPP (Gross Domestic Product at Purchasing Power Parity) and GDP per capita PPP. ( $\mathrm{r}=0.712$, $\mathrm{p}<0.001$; $\mathrm{r}=0.618$, $\mathrm{p}<0.001$; $\mathrm{r}=0.701, \mathrm{p}<0.001 ; \mathrm{r}=0.614, \mathrm{p}<0.001)$. 
Tab. 3. The most cited articles according to total citations on non-invasive mechanical ventilation.

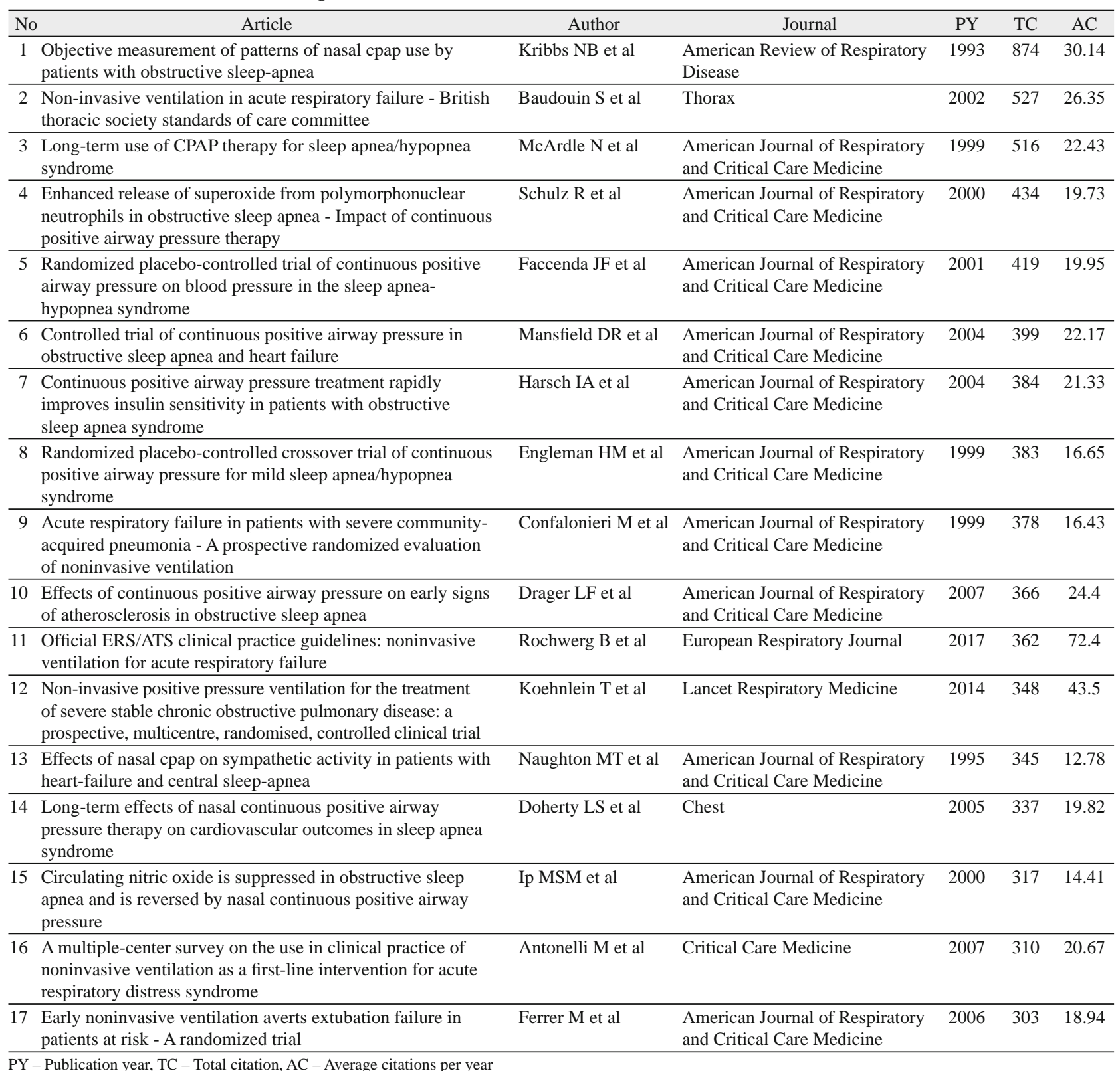

\section{Active authors}

Most productive authors who wrote more 30 and more articles were Nava S ( $n=48)$, Pepin JL $(n=46)$, Stradling JR $(n=39)$, Brochard L $(n=37)$, Conti G $(n=32)$, Windisch W $(n=31)$, and Navalesi P $(n=30)$.

\section{Active institutions}

Most generative institiuons published 20 and more articles were University of Toronto ( $n=55)$, Inserm $(n=40)$, University of Sydney ( $n=39$ ), University of Barcelona ( $n=38)$, Henri-Mondor University Hospital ( $n=33)$, University of Milano ( $n=33)$, University Cattolica Sacro Cuore $(n=30)$, Massachusetts Gen Hospital $(n=29)$, Royal
Prince Alfred Hospital ( $n=27)$, University of Sao Paulo ( $n=27)$, University of Groningen ( $n=24)$, University of Laval $(n=24)$, Churchill Hospital ( $n=23)$, University of California San Diego ( $n=23)$, Hospital of Clinic Barcelona $(n=22)$, St Michaels Hospital $(n=22)$, Harvard University $(n=21)$, University of Paris $06(n=21)$, Case Western Reserve University ( $n=20)$, University of Zurich ( $n=20)$.

\section{Active journals}

208 separate journals published 2847 articles about NIV. Journals that host ten and more articles, total citation numbers, and average citation per article are depicted in Table 2. The Citation network between these journals is presented in Figure 5 . 
Tab. 4. The most frequently used keywords on non-invasive mechanical ventilation.

\begin{tabular}{|c|c|c|c|c|c|}
\hline Key words & $\begin{array}{c}\text { No of } \\
\text { uses }\end{array}$ & Key words & $\begin{array}{c}\text { No of } \\
\text { uses }\end{array}$ & Key words & $\begin{array}{c}\text { No of } \\
\text { uses }\end{array}$ \\
\hline Noninvasive ventilation (NIV) & 731 & Asthma & 26 & Hypoventilation & 14 \\
\hline Continuous positive airway pressure (CPAP) & 484 & Endotracheal intubation & 26 & Outcome & 14 \\
\hline Obstructive sleep apnea & 235 & Infant (s) & 26 & Positive pressure ventilation & 14 \\
\hline CPAP & 180 & Hypoxemia & 25 & Pressure support & 14 \\
\hline Acute respiratory failure & 176 & Critical care & 22 & Pulmonary edema & 14 \\
\hline Chronic obstructive pulmonary disease & 147 & Humidification & 22 & Respiratory therapy & 14 \\
\hline Mechanical ventilation & 127 & Meta-analysis & 22 & Acute hypercapnic respiratory failure & 13 \\
\hline High-flow nasal cannula & 113 & Sleep-disordered breathing & 22 & Apnea & 13 \\
\hline Respiratory failure & 113 & Neuromuscular disease & 20 & Bronchoscopy & 13 \\
\hline Sleep apnea & 108 & Obstructive sleep apnoea syndrome & 20 & Cardiac surgery & 13 \\
\hline Copd & 81 & Acute lung injury & 19 & Heart rate variability & 13 \\
\hline Respiratory insufficiency & 71 & Emergency department & 19 & Heated humidifier & 13 \\
\hline Obstructive sleep apnoea & 66 & Intensive care & 19 & Nebulizer & 13 \\
\hline Nasal continuous positive airway pressure & 63 & Positive-pressure respiration & 19 & Oxidative stress & 13 \\
\hline Ventilation & 53 & Amyotrophic lateral sclerosis & 18 & Oxygen & 13 \\
\hline Obstructive sleep apnea syndrome & 52 & Blood pressure & 18 & Pulmonary rehabilitation & 13 \\
\hline Hypercapnia & 51 & Intubation & 18 & Reintubation & 13 \\
\hline Noninvasive mechanical ventilation & 49 & Oxygen inhalation therapy & 18 & Emergency medical services & 12 \\
\hline Noninvasive positive pressure ventilation & 49 & Randomized controlled trial & 18 & HFNC & 12 \\
\hline NIV & 48 & Respiratory distress & 18 & Respiratory distress syndrome & 12 \\
\hline Adherence & 47 & Treatment & 18 & Respiratory mechanics & 12 \\
\hline Compliance & 43 & Cystic fibrosis & 17 & Survey & 12 \\
\hline Children & 41 & Exercise & 17 & Tracheostomy & 12 \\
\hline Chronic respiratory failure & 39 & Heart failure & 17 & Central sleep apnea & 11 \\
\hline Polysomnography & 39 & Home mechanical ventilation & 17 & Dyspnea & 11 \\
\hline Sleep & 39 & Nasal CPAP & 17 & Gas exchange & 11 \\
\hline Weaning & 38 & Child & 16 & $\mathrm{ICU}$ & 11 \\
\hline Bilevel positive airway pressure & 37 & Exacerbation & 16 & Masks & 11 \\
\hline Obesity hypoventilation syndrome & 35 & Extubation & 16 & Nasal mask & 11 \\
\hline Mortality & 34 & Hypertension & 16 & Patient-ventilator asynchrony & 11 \\
\hline Osa & 34 & Intubation & 16 & Positive airway pressure & 11 \\
\hline Pediatric (s) & 34 & Intensive care unit & 16 & Positive end-expiratory pressure & 11 \\
\hline Pneumonia & 34 & Monitoring & 16 & Sedation & 11 \\
\hline Oxygen therapy & 33 & Patient-ventilator interaction & 16 & Artificial respiration & 10 \\
\hline Bronchiolitis & 32 & Sleepines & 16 & Auto-CPAP & 10 \\
\hline Obesity & 31 & BIPAP & 15 & Complications & 10 \\
\hline Work of breathing & 31 & Congestive heart failure & 15 & COVID-19 & 10 \\
\hline Sleep apnoea & 30 & Pressure support ventilation & 15 & High-flow oxygen therapy & 10 \\
\hline Acute respiratory distress syndrome & 29 & ARDS & 14 & Hypoxia & 10 \\
\hline Sleep apnea syndrome (s) & 29 & Cardiogenic pulmonary edema & 14 & Pediatric intensive care unit & 10 \\
\hline Helmet & 28 & CPAP adherence & 14 & Prognosis & 10 \\
\hline Quality of life & 27 & Face mask & 14 & Survival & 10 \\
\hline
\end{tabular}

\section{Citation analysis}

Among the articles published between 1980 and 2020, the first 17 articles with the highest number of citations (more than 300 citations) according to the total number of citations are presented in Table 3. In the last column of Table 3, the average number of citations per year is given.

\section{Co-citation analysis}

There were a total of 33325 studies cited in the references section of all 2847 articles analyzed. The first seven studies that received the most co-citations from these studies (more than 150 citations) were Brochard L (1995) (Number of co-citations, NC: 297), Sullivan CE (1981) (NC: 244), Johns MW (1991) (NC: 205), Young T (1993) (NC: 185), Plant PK (2000) (NC: 183), Kramer N (1995) (NC: 153), Bott J (1993) (NC: 150) (7-13).

\section{Trend topics}

The authors used 3432 different keywords in all 2847 articles published on NIV. Of these words, 126 different keywords were used in at least ten different articles (Tab. 4). The network visu- 


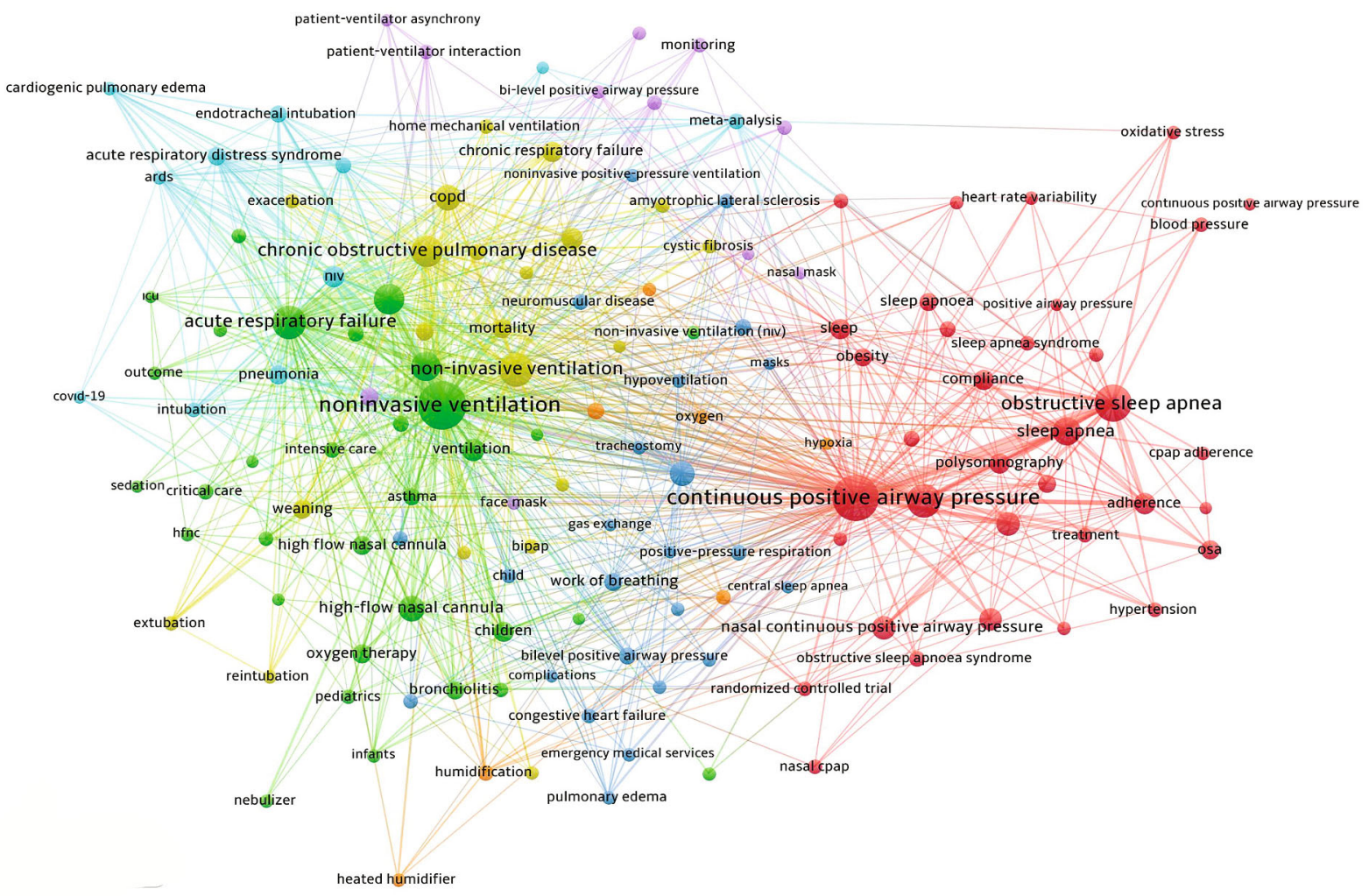

Fig. 6. Network visualization map for cluster analysis based on keyword analysis on noninvasive ventilation. Colors show clustering. Keywords in the same cluster are of the same color.

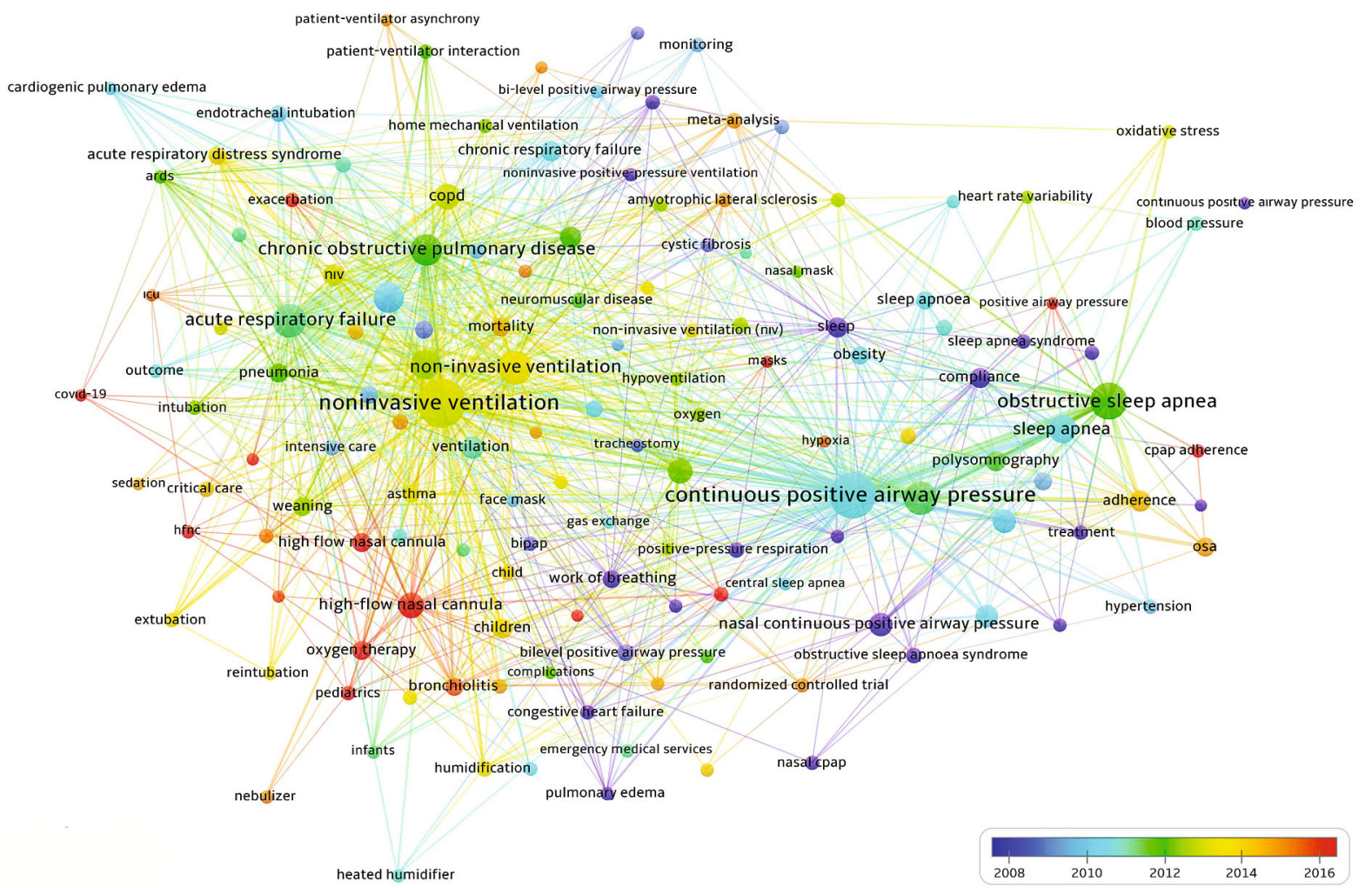

Fig. 7. Network visualization map for trends on noninvasive ventilation. Indicator shows current publications from blue to red (blue-greenyellow-red). 


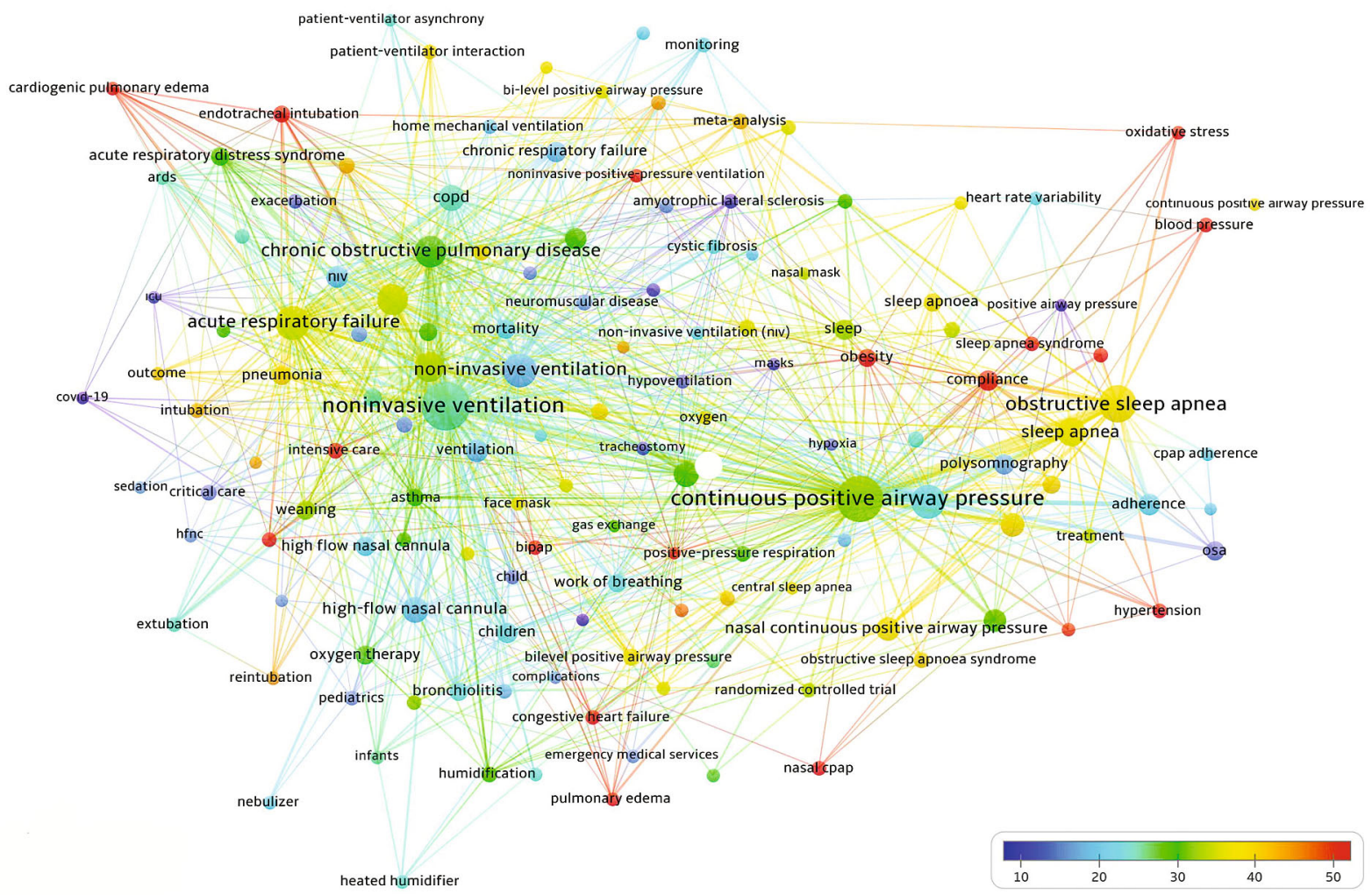

Fig. 8. Network visualization map of the most frequently cited topics on noninvasive ventilation. The number of citations from blue to red increases.

alization map of these keyword clusters is presented in Figure 6. The trend visualization network map is shown in Figure 7, and the citation network visualization map is illustrated in Figure 8.

\section{Discussion}

We found that the number of articles published about NIV is increasing day by day. As we showed in Figure 2, there were 0-50 articles (mean: 23) per year between 1980 and 1999, rising with a linear trend. The number of articles gained speed with the new millennium, and over a hundred papers were published every year after 2010. Non-linear regression analyses show that the number of articles will continue to increasing exponential trend (Fig. 2). We estimated that the number of publications would continue to increase and rise over three hundred by 2025 . We think that it can be associated with two major topics. Firstly, we know that the number of intensive care units (ICU) is increasing over the years, correlating with the aging of the population and associated comorbidities. Kelly et al. stated that aging, increasing obesity, and disease candidates for treatment with new treatment modalities would require increasing ICUs (14). Considering factors such as smoking and air pollution, and microorganisms that threaten the respiratory tract (such as COVID), it is not difficult to predict that the need for intensive care and ventilators will grow. The second one is the expanding indications of NIV. Although NIV is primarily used for hypercapnic respiratory failure, especially for exacerbations of chronic obstructive pulmonary disease (COPD) and obstructive sleep apnea
(OSA), it gains new usage areas such as neuromuscular diseases, cardiogenic pulmonary edema, hypoxemic respiratory failure (such as pneumonia), weaning, post-operative state, and support of bronchoscopy (15). Other benefits compared with invasive ventilation, such as reduced complication rate, reduction in the hospital stay, and mortality, also support the use of NIV (16). Taken together, consistent with our findings, we can expect that the use of NIV and, in correlation, the number of articles on NIV will increase.

Development degree seems like a good reflector of productivity. Sixteen of the twenty most productive countries are developed countries. The remaining four are developing countries (Turkey, China, India, and Brazil) with big economies. Correlation analysis showed that economic power is one of the most influential factors on scientific productivity in $\operatorname{NIV}(5,17,18)$. When we examined the co-authorship cooperation of countries on NIV, we found that cooperation based on geographical countries does not significantly affect article production. Collaborations were generally made in small clusters and were seen in the geographical neighborhood (Italy-Spain-Tunisia) and (France-Belgium-Switzerland) clusters (Fig. 4a). The density map created according to the collaboration score between countries showed that the most collaborative countries are France, the USA, Italy, UK, Canada, Spain, Switzerland, and Germany, respectively (Fig. 4b).

The most active authors and institutions were also consistent with countries. All active authors listed above are from Europe and North America. Similarly, only one institution, the University of Sao Paolo, was located outside Europe and North America. 
$218-226$

The journals that published the most articles on NIV were determined as Chest, Respiratory Care, Sleep and Breathing, European Respiratory Journal, Intensive Care Medicine, American Journal of Respiratory and Critical Care Medicine, Pediatric Pulmonology, Thorax, Respiratory Medicine, and Critical Care Medicine, respectively. When the citation analyzes of the journals were evaluated, the most influential journals according to the average number of citations per article they published were American Journal of Respiratory and Critical Care Medicine, American Review of Respiratory Disease, Thorax, Chest, European Respiratory Journal, Critical Care Medicine, and Intensive Care Medicine, respectively. Not surprisingly, the most preferred and most-cited journals on NIV are respiratory diseases and intensive care journals. These are also high impacted journals in their disciplines. This may guide authors who want to publish papers about NIV and reach more readers.

The most commonly used keywords were non-invasive ventilation, chronic obstructive pulmonary disease, continous positive airway pressure, acute respiratory failure, and obstructive sleep apnea. This reflects the most frequently studied topics related to NIV, similar to Cortegiani's study (19). Cluster network visualization map gave ideas also about other interested diseases. Chronic respiratory failure, obesity, cystic fibrosis, neuromuscular disorders, pneumonia, and weaning were seemed less popular but candidate issues for new studies.

According to our knowledge, this is the first comprehensive study that examined the dynamics of literature about NIV bibliometrically. Previously, Cortegiani and colleagues planned research with a similar curiosity and defined ten impressive articles published on NIV to identify research topics related to NIV. They stated that NIV use on COPD exacerbations has solid evidence and other issues need well-designed randomized studies. They also make a suggestion list for future studies (19).

Our study has the advantage of including approximately all studies since NIV started to be used. Besides, using comprehensive statistical methods such as keyword, cluster, correlation, and regression analysis improves the power of our research. We can say that it draws a detailed framework to the history of NIV.

We did not use the Pubmed index because it does not allow us to make citation and co-citation analyses. We also did not use the Scopus index because it includes studies with low effect levels. So, we used only the WoS index. This may be a limitation of our study. But, it should also be considered that WoS is more commonly preferred in bibliometric analyses conducted in recent years.

\section{Conclusion}

NIV technology and new devices are developing day by day. In addition, new areas of use have been defined by doctors. All these bring about new and different studies on NIV. We believe the present study which summarized the history and development of NIV literature, will guide the authors who want to study this area.

\section{References}

1. Heffner JE. The story of oxygen. Respir Care 2013; 58 (1): 18-31. DOI: 10.4187/respcare.01831. PMID: 23271817.
2. Hillberg RE, Johnson DC. Noninvasive ventilation. N Engl J Med 1997 Dec 11; 337 (24): 1746-1752. DOI: 10.1056/NEJM199712113372407. PMID: 9392701.

3. Pierson DJ. History and epidemiology of noninvasive ventilation in the acute-care setting. Respir Care 2009; 54 (1): 40-52. PMID: 19111105.

4. De Bellis N. Bibliometrics and citation analysis: from the science citation index to cybermetrics: scarecrow press; 2009

5. Doğan G, Karaca O. Análise bibliométrica no campo da anestesiologia no período de 2009-2018 [A bibliometric analysis of the field of anesthesia during 2009-2018]. Braz J Anesthesiol 2020; 70 (2): 140-152. Portuguese. DOI: 10.1016/j.bjan.2020.02.003. Epub 2020 May 22. PMID: 32499046.

6. The World Bank (2020). Website https: //data.worldbank.org/indicator/ NY.GDP.MKTP.CD [accessed 1 October 2020].

7. Brochard L, Mancebo J, Wysocki M et al. Noninvasive ventilation for acute exacerbations of chronic obstructive pulmonary disease. N Engl J Med 1995; 333 (13): 817-822. DOI: 10.1056/NEJM199509283331301. PMID: 7651472.

8. Sullivan CE, Issa FG, Berthon-Jones M, Eves L. Reversal of obstructive sleep apnoea by continuous positive airway pressure applied through the nares. Lancet 1981; 1 (8225): 862-865. DOI: 10.1016/s0140-6736 (81)921401. PMID: 6112294.

9. Johns MW. A new method for measuring daytime sleepiness: the Epworth sleepiness scale. Sleep 1991; 14 (6): 540-545. DOI: 10.1093/sleep/14.6.540. PMID: 1798888.

10. Young T, Palta M, Dempsey J, Skatrud J, Weber S, Badr S. The occurrence of sleep-disordered breathing among middle-aged adults. N Engl J Med 1993; 328 (17): 1230-1235. DOI: 10.1056/NEJM199304293281704. PMID: 8464434.

11. Plant PK, Owen JL, Elliott MW. Early use of non-invasive ventilation for acute exacerbations of chronic obstructive pulmonary disease on general respiratory wards: a multicentre randomised controlled trial. Lancet 2000; 355 (9219): 1931-1935. DOI: 10.1016/s0140-6736(00)02323-0. PMID: 10859037.

12. Kramer N, Meyer TJ, Meharg J, Cece RD, Hill NS. Randomized, prospective trial of noninvasive positive pressure ventilation in acute respiratory failure. Am J Respir Crit Care Med 1995; 151 (6): 1799-1806. DOI: 10.1164/ ajrccm.151.6.7767523. PMID: 7767523.

13. Bott J, Carroll MP, Conway JH et al. Randomised controlled trial of nasal ventilation in acute ventilatory failure due to chronic obstructive airways disease. Lancet 1993; 341 (8860): 1555-1557. DOI: 10.1016/0140-6736 (93)90696-e. PMID: 8099639.

14. Kelly FE, Fong K, Hirsch N, Nolan JP. Intensive care medicine is 60 years old: the history and future of the intensive care unit. Clin Med (Lond) 2014; 14 (4): 376-379. DOI: 10.7861/clinmedicine.14-4-376. PMID: 25099838; PMCID: PMC4952830.

15. British Thoracic Society Standards of Care Committee. Non-invasive ventilation in acute respiratory failure. Thorax 2002; 57 (3): 192-211. DOI: 10.1136/thorax.57.3.192. PMID: 11867822; PMCID: PMC1746282.

16. Brochard L. Mechanical ventilation: invasive versus noninvasive. Eur Respir J Suppl 2003; 47: 31-37. DOI: 10.1183/09031936.03.00050403. PMID: 14621115.

17. King DA. The scientific impact of nations. Nature 2004; 430 (6997): 311-316. DOI: 10.1038/430311a. Erratumin: Nature 2004; 432(7013): 8. PMID: 15254529.

18. https://data.worldbank.org/indicator/IP.JRN.ARTC.SC?year_low_ desc $=$ true.

19. Cortegiani A, Russotto V, Antonelli M et al. Ten important articles on noninvasive ventilation in critically ill patients and insights for the future: A report of expert opinions. BMC Anesthesiol 2017; 17 (1): 122. DOI: 10.1186/ s12871-017-0409-0. PMID: 28870157; PMCID: PMC5584318.

Received September 18, 2021. Accepted November 23, 2021. 